\title{
Pausological aspects of Guatemalan children's narratives
}

\author{
MARY R. BASSETT and DANIEL C. O'CONNELL \\ Saint Louis University, Saint Louis, Missouri 63103
}

\begin{abstract}
Three groups of 22 second-grade Guatemalan children were tape-recorded as they spontaneously narrated the story of a day in the life of a family they had selected from 15 clay dolls. The three groups represented two socioeconomic status (SES) levels in Guatemala City and a rural Guatemalan group. Urban-high and urban-low SES groups showed the greatest differences: the urban-high group used shorter silent pauses and a slower articulation rate than the other two groups, while the urban-low group used significantly longer silent pauses and a faster articulation rate. The rural group fell between the two urban groups on these measures. The SES level is clearly discriminated by silent pause length and articulation rate.
\end{abstract}

Language differences associated with socioeconomic status (SES) characteristics have been observed since long before the production of My Fair Lady; however, systematic investigation of the precise nature and cause of these differences has only recently begun. Among the first and most cited of these differences have been those discussed in the research of Bernstein (1971). For approximately 15 years, he has been elaborating upon the concept of language codes associated with SES. The consistent message that can be derived from his work is that lower class speech is to be considered inferior to speech used by middle class speakers.

In an empirical test of these hypotheses published by Bernstein (1962), the relationship of temporal measures of speech to social class was examined. However, the methodology renders the results inconclusive, since practice sessions were held with one group but not with the other. Also, there was prompting during the recording sessions. Knowledge of and interest in the topic on the part of one experimental group rather than the other could plausibly have influenced results. It was concluded that the lower SES group used more frequent and shorter pauses than the middle class speakers.

Additional studies on SES and temporal speech measures have largely yielded results contrary to those of Bernstein. Hawkins (1973, pp. 235-250) found that higher SES 6- and 7-year-olds use more frequent pauses, as well as pauses of more moderate length, than do lower SES children of these ages. Jones and McMillan (1973) found somewhat similar results: Middle class 5-year-olds use fewer and shorter pauses than lower class 5-yearolds. The findings of Bassett, O'Connell, and Monahan (1977) were not inconsistent with these results. They found that 5-year-olds from high SES backgrounds used more frequent but shorter silent pauses than the low SES group, although these differences no longer appeared among SES groups of 7-year-olds.
It is possible that speakers of the same basic language living in different parts of the world may be differentiated by temporal speech measures, as well as may be the various groups within the national speech community boundaries. To date, we know of no attempt to differentiate U.S., Canadian, British, or other speakers of English in this way, although references to possible differences in the SES structure within the various countries have been made.

The present research moves to a different basic language (Spanish) and to a country where SES boundaries are clear and nonoverlapping. Relatively little research on the temporal aspects of speech has been done in this language. In addition, the present study compares rural and urban speakers within the country.

\section{METHOD}

The subjects of this study were 66 second-grade children living in Guatemala, Central America. They were all native speakers of Guatemalan Spanish. There were three groups of 22 children each, 11 boys and 11 girls in each group. Twentytwo children were from a rural town (population 6,000), and 44 were from Guatemala City, a large urban area. The urban groups represented two distinct SES levels, the rich (urban-high) and the poor (urban-low). The rural children's SES level was quite similar to that of the urban-low group. The mean ages of the children were: urban-high, 8 years, 1 month; urban-low, 8 years, 1 month; rural, 8 years, 5 months.

Tape-recorded unrehearsed speech samples were obtained from each child as he or she spoke to the experimenter. The experimenter was the first author, a proficient nonnative speaker of Guatemalan Spanish. Speech was elicited by use of 15 ceramic figurines and a cardboard floor plan of a house. The figurines were of varying sizes, in order to indicate adults and children of several different ages. The features were intentionally vague. All of the dolls were made of clay with a clear glaze, resulting in a slightly pink hue.

Each child was asked to select the dolls that would best represent a family living in the house. It was emphasized that this did not mean that all of the dolls had to be used, but only those thought to belong to a family that might be living in this house. Thereupon the child was instructed to describe 
in detail the activities of each person in the family during the course of 1 day in the life of this family.

Verbatim transcripts were prepared from the tapes and time variables were measured objectively from the graphic records produced by a Brüel and Kjaer af spectrometer and level recorder, as described in greater detail elsewhere (Kowal, O'Connell, \& Sabin, 1975; O'Connell \& Kowal, 1972). A minimum length of $270 \mathrm{msec}$ was accepted as the cutoff point for silent pauses.

\section{RESULTS}

Significant differences for mean silent pause length ( $\mathrm{p}<.01)$, mean silent pause length per syllable $(\mathrm{p}<$ $.005)$, and articulation rate (syllables per second) $(\mathrm{p}<$ .01 ) were obtained in a 3 by 2 (SES by sex) analysis of variance (Table 1). Means and standard deviations for these variables are presented in Table 2 . There were no significant differences due to the factor of sex for any variable, nor were there any significant interaction effects.

Implementation of the Scheffé test further located these differences. For the measure of mean silent pause length, the urban-low and rural groups differed significantly $(p<.03)$, and urban-low differed significantly from the urban-high group $(\mathrm{p}<.05)$ (Table 1). Likewise, the Scheffé test located similar differences for the mean silent pause length per syllable. This is a measure adjusted for the story length and actually compares the amount of speech to the amount of time spent pausing. The results show the urban-low to differ significantly from the rural $(p<.01)$ and urbanhigh $(p<.05)$ groups (Table 1). The Scheffé test also located one significant difference for the measure of articulation rate, that between the urban-low and urbanhigh groups $(\mathrm{p}<.01)$ (Table 1$)$.

It is noteworthy that there was no significant effect for speech rate, although the measures of silent pause length and articulation rate were significantly different. The direction of the differences of the two measures balanced each other in such a way as to make the measure of speech rate nonsignificant. The urban-low group made up the time lost with long silent pauses by articulating more rapidly than the other groups, so that the overall syllable per second speech rate was equalized. Within the speech corpus, syllable production was distributed over total speaking time in characteristically different ways across the SES groups.

The percentage of pauses of varying lengths presents a revealing picture of the manner in which each group used silent pause time (Figure 1). Silent pauses in the
Table 1

Significance Levels for Analysis of Variance and Scheffé Tests

\begin{tabular}{|c|c|c|c|}
\hline \multicolumn{2}{|l|}{ ANOVA } & \multicolumn{2}{|l|}{ Scheffé } \\
\hline Measure & $\mathrm{p}$ & Groups & $\mathrm{p}$ \\
\hline $\begin{array}{l}\text { Mean silent pause } \\
\text { length }\end{array}$ & .01 & $\begin{array}{l}\text { Urban-low vs. rural } \\
\text { Urban-low vs. urban-high }\end{array}$ & $\begin{array}{l}.03 \\
.05\end{array}$ \\
\hline $\begin{array}{l}\text { Silent pause length } \\
\text { per syllable }\end{array}$ & .005 & $\begin{array}{l}\text { Urban-low vs. rural } \\
\text { Urban-low vs. urban-high }\end{array}$ & $\begin{array}{l}.01 \\
.05\end{array}$ \\
\hline Articulation rate & .01 & Urban-low vs. Urban-high & .01 \\
\hline
\end{tabular}

narratives of the urban-low group were greater than $2,030 \mathrm{msec}(2.03 \mathrm{sec}) 41.7 \%$ of the time, whereas silent pauses in the urban-high narratives exceeded this length only $26.9 \%$ of the time. On the other hand, $73.1 \%$ of the silent pauses in urban-high group narratives were $2,000 \mathrm{msec}(2 \mathrm{sec})$ or less, while only $58.3 \%$ of silent pauses in urban-low group narratives were of this length or shorter. The rural group occupied an intermediate position between the other two groups.

\section{DISCUSSION}

The results of this research are straightforward, with only two variables yielding significant results. The length of silent pauses and articulation rate discriminate among groups. The speech of the urban-low group was characterized by long silent intervals between rapidly articulated vocalization segments. By comparison, the urban-high group used a more evenly paced pattern of shorter silent pauses with a slower articulation rate. This even pace suggests greater fluency in the urban-high group.

These results are slightly different from those found previously between SES groups in the U.S. (Bassett et al., 1977). The results are not directly comparable because of the different speech tasks involved; however, the type and direction of differences may be considered. In the U.S. study, significant differences found at the kindergarten level were no longer evident at the second grade, but this leveling with school progress did not occur for Guatemalan children. All children studied in the Guatemalan sample were in the second grade at the time of recording. If there is a leveling effect associated with education, it is not evident at the second-grade level in the present study. Thus, in order to evaluate the distinctive and significantly different variables associated with SES, it is necessary in this case to compare second-grade Guatemalan children with kindergarten groups in the U.S. study. In both cases, the lowest SES group used longer silent pause lengths; however, only the Guatemalan Spanish-speaking sample showed a significant difference in articulation rate.

Care must be taken to avoid the conclusion that the apparently less fluent speech of the urban-low group indicates lack of intellectual ability. It may indeed reflect some impoverishment, but this is environmental, not genetic. A recent study shows that children born to low SES parents but raised

Table 2

Means and Standard Deviations for Significant Variables

\begin{tabular}{|c|c|c|c|c|c|c|}
\hline \multirow[b]{2}{*}{ Measure } & \multicolumn{2}{|c|}{ Urban-High Group } & \multicolumn{2}{|c|}{ Urban-Low Group } & \multicolumn{2}{|c|}{ Rural Group } \\
\hline & Mean & SD & Mean & SD & Mean & SD \\
\hline Mean silent pause length & $2,712.50$ & $1,468.71$ & $4,537.18$ & $3,398.98$ & $2,588.32$ & $1,372.76$ \\
\hline Silent pause length per syllable & 349.54 & 202.28 & 509.04 & 432.47 & 310.64 & 176.26 \\
\hline Articulation rate & 4.03 & 1.07 & 4.75 & .66 & 4.56 & .56 \\
\hline
\end{tabular}




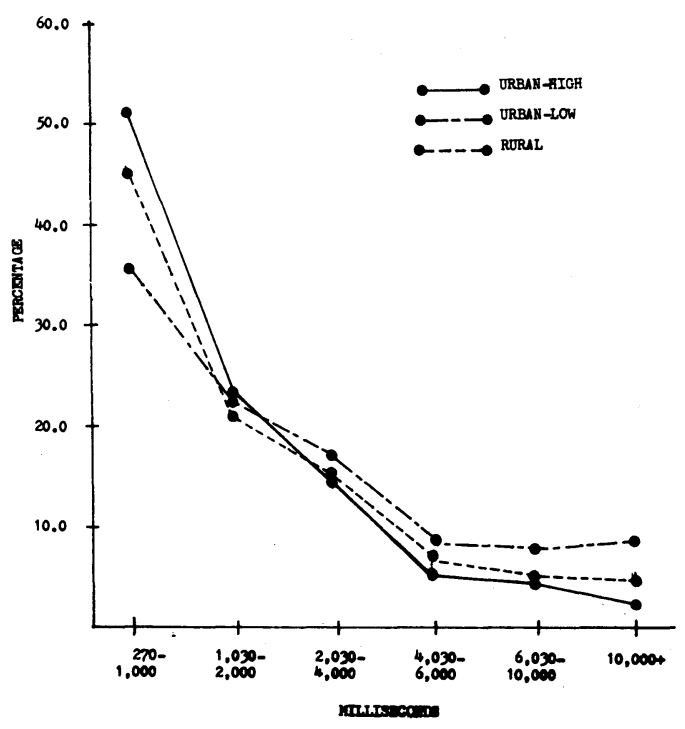

Figure 1. Percentage of silent pauses of various lengths.

in more affluent families develop the same intellectual skills as the natural children of the affluent parents (Schiff, Duyme, Dumaret, Stewart, Tomkiewicz, \& Feingold, 1978).

It was thought that, perhaps, the selection of larger figurine families by urban-low children would correspond to the use of longer silent pauses, since these children had more figurines to manipulate on the floor plan. However, upon investigation, it was concluded that this could not have been the case. The mean numbers of figurines used were 8 and 7 for girls and boys, respectively, in the rural group, and 11 and 12 for girls and boys, respectively, in the urban-low group. But the corresponding means for girls and boys in the urban-high group were 5 and 13 , respectively. Thus, if the number of dolls used to tell the story had influenced speech variables, there should have been a significant difference for the factor of sex in the urban-high group. No such difference was found to exist. Therefore, it is assumed that the number of figurines selected to represent the family did not cause artifactual results to emerge in the speech variables. Undoubtedly, these differences do reflect systematic characteristics beyond those uncovered by the present methodology.

Finally, it is interesting to note that, although the total number of figurines selected to represent a family did not influence the pause patterns within or between groups, the speech task itself did result in comparatively longer overall silent pause lengths when compared to other types of speecheliciting tasks. In the U.S. study, speech was elicited in response to a set of nine cartoon pictures that the child was asked to arrange and tell a good story about. Mean silent pause length for high, middle, and low SES groups combined was .96 sec (Bassett et al., 1977, p. 167). This is very short when compared to the combined mean silent pause length of $3.28 \mathrm{sec}$ in the present study, which is quite long even when compared to the kindergarten group of the previous research $(2.01 \mathrm{sec})$.

These results suggest that the present speech task was more complex than the cartoon pictures and required more on-going planning time to produce the narratives. This is especially noteworthy in light of the previously discussed evidence that additional doll manipulation was not related to longer silent pause lengths.

In conclusion, evidence across linguistic and cultural boundaries and across speech tasks has shown that children from poorer families tend to pause comparatively longer than more affluent children of the same age. It would be of interest to study how and/or if these or similar SES differences persist into adulthood.

\section{REFERENCES}

Bassett, M. R., O’Connell, D. C., \& Monahan, W. J. Pausological aspects of children's narratives. Bulletin of the Psychonomic Society, 1977, 9, 166-168.

Bernstein, B. Linguistic codes, hesitation phenomena and intelligence. Language and Speech, 1962, 5, 31-46.

Bernstein, B. Class, codes and control (Vol. 1). London: Routledge \& Kegan Paul, 1971.

Hawkins, P. R. The influence of sex, social class and pauselocation in the hesitation phenomena of seven-year-old children. In B. Bernstein (Ed.), Class, codes and control (Vol. 2). London: Routledge \& Kegan Paul, 1973.

Jones, P. A., \& McMillan, W. B. Speech characteristics as a function of social class and situational factors. Child Development, 1973, 44, 119-121.

Kowal, S. H., O’Connell, D. C., \& Sabin, E. J. Development of temporal patterning and vocal hesitations in spontaneous narratives. Journal of Psycholinguistic Research, 1975, 4, 195-207.

O'Connell, D. C., \& Kowal, S. H. Cross-linguistic pause and rate phenomena in adults and adolescents. Journal of Psycholinguistic Research, 1972, 1, 155-164.

Schiff, M., Duyme, M., Dumaret, A., Stewart, J., Tomkiewicz, S., \& Feingold, J. Intellectual status of working-class children adopted early into upper-middle-class families. Science, 1978, 200, 1503-1504.

(Received for publication August 7, 1978.) 